\title{
HISTÓRIA E MEMÓRIA EM SALA DE AULA: AS IDEIAS DOS ALUNOS SOBRE AS MANIPULAÇÕES FOTOGRÁFICAS NO GOVERNO DE STÁLIN (1923-1954)
}

\author{
HISTORY AND MEMORY IN THE CLASSROOM: THE IDEAS OF STUDENTS \\ ABOUT THE PHOTOGRAPHIC MANIPULATIONS DURING STALIN'S \\ GOVERNMENT (1923-1954)
}

Andreya Susane Seiffert ${ }^{1}$

\begin{abstract}
RESUMO: Este artigo é resultado de pesquisa desenvolvida com alunos do segundo ano do ensino médio na turma na qual realizei o estágio obrigatório da disciplina Estágio com Docência em História IIII da Universidade do Estado de Santa Catarina (UDESC). A proposta da disciplina era aliar ensino e pesquisa. O tema escolhido para investigação e análise através do presente artigo foi a manipulação fotográfica ocorrida no governo de Stálin. Este trabalho apresenta uma interpretação acerca das respostas dos alunos quando questionados sobre o motivo de tais intervenções e se é realmente possível apagar alguém da História. Expõe, ainda, a relação que os estudantes travaram entre Memória e História e discute a importância do ensino de História em contribuir para o aperfeiçoamento da consciência histórica.
\end{abstract}

Palavras-chave: Ensino de História. Memória. Stalinismo.

\begin{abstract}
This article is the result of a study developed with high school students as a part of my compulsory internship from the Internship with Teaching in History III course of the Universidade do Estado de Santa Catarina (UDESC).The proposal of the course was to join teaching and research. The theme chosen for research and analysis in the present article was the photographic manipulation that occurred during Stalin's government. This paper presents an interpretation about the students' responses when asked about the reason behind those interventions and if it really is possible to erase someone from history. It also shows the relationship that students caught between memory and history, and discuss the importance of history teaching to the development of historical consciousness.
\end{abstract}

Keywords: History Teaching. Memory. Stalinism.

${ }^{1}$ Graduada em História pela Universidade do Estado de Santa Catarina (UDESC).

História \& Ensino, Londrina, v. 17, n. 1, p. 167-181, jan./jun. 2011 
Assim que fossem reunidas e classificadas todas as correções consideradas necessárias a um dado número do Times, aquela edição era reimpressa, destruído o número original, e o exemplar correto colocado no arquivo em seu lugar. Esse processo de alteração contínua aplicava-se não apenas a jornais, como também a livros, publicações periódicas, panfletos, cartazes, folhetos, filmes, bandas de som, caricaturas, fotografias - a toda espécie de literatura ou documentação que pudesse ter o menor significado político ou ideológico. Dia a dia e quase minuto a minuto o passado era atualizado. Desta forma, era possível demonstrar, com prova documental, a correção de todas as profecias do Partido; jamais continuava no arquivo uma notícia, artigo ou opinião que entrasse em conflito com as necessidades do momento. Toda a história era um palimpsesto, raspado e reescrito tantas vezes quantas fosse necessário (ORWELL, 2005, p.41).

\section{Introdução}

"1984" é um relato ficcional. Orwell, contudo, inspirou-se em regimes totalitários para escreve-lo, e há quem diga que um dos exemplos seria a União das Repúblicas Socialistas Soviéticas (URSS) durante o governo de Stálin (1923-1954).

O personagem principal do livro, Winston, trabalha na seção de correções - ou alterações, como o governo prefere. Seu trabalho consiste em "ajustar" as fontes de acordo com o interesse de cada período. O Departamento de Registro no qual Winston trabalha faz parte do Ministério da Verdade, incumbido de fornecer todas as informações aos cidadãos da Oceania.

No mundo criado por Orwell, todos são vigiados constantemente inclusive em suas casas, com as "teletelas", espécie de televisor que transmite a programação oficial do governo e funciona também como câmera para vigiar os cidadãos. Até os pensamentos são controlados, através de uma Polícia especial. Quem ousar questionar o Partido é "vaporizado": As pessoas simplesmente desapareciam, sempre durante a noite. O nome do cidadão era removido dos registros, suprimida toda menção dele, negada sua existência anterior, e depois esquecido (ORWELL, 2005, p.21). 
Ao realizar meu estágio no Colégio de Aplicação da Universidade Federal de Santa Catarina (UFSC) com a turma do segundo ano do ensino médio (2A), composta por vinte e dois alunos e sob supervisão da professora Ana Lice Brancher, constatei que é legítimo o conhecido ditado que diz "é ensinando que se aprende". Foi preciso estudar muito as revoluções Mexicana, Russa e Primeira Guerra Mundial, temas propostos pela professora da turma para ministrarmos. Surpreendeu-me quando pesquisando imagens sobre o período conhecido como stalinismo:

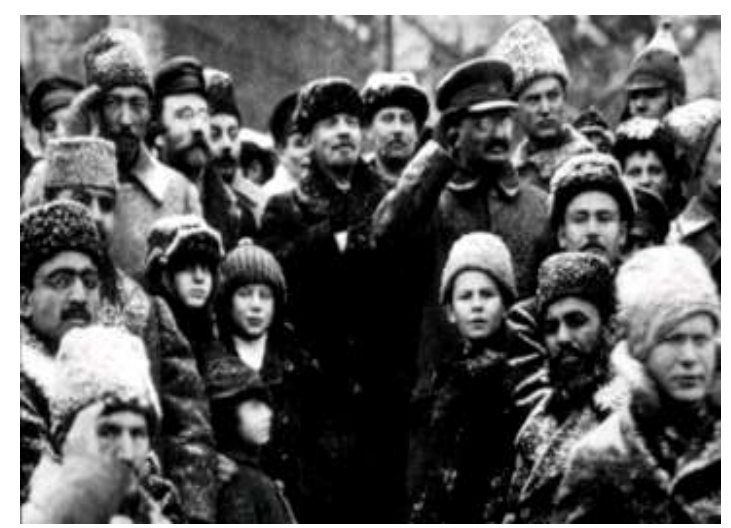

Imagem 01: Lênin e Trotsky celebrando o segundo aniversário na Praça Vermelha².

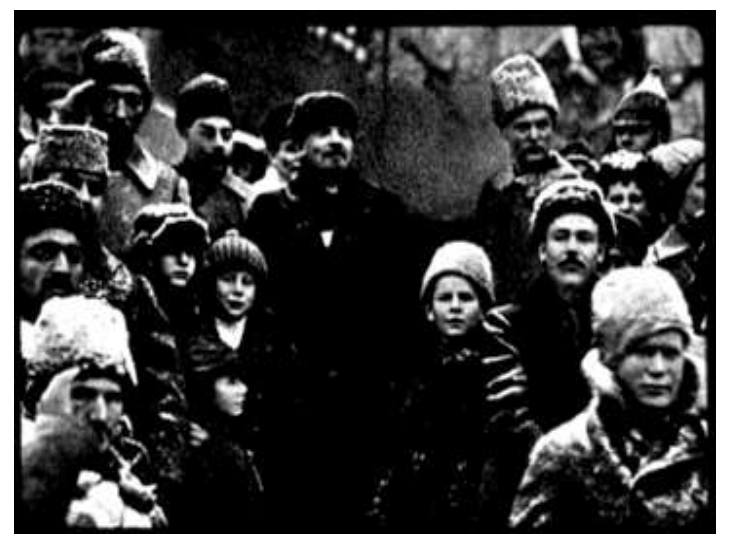

Imagem 02: Trotsky foi "apagado".

2 As fotos selecionadas circulam amplamente na Internet. Ver, por exemplo, Wikipédia, http://spectrum.weblog.com.pt ， http://www.charonboat.com/item/132/page2.htm e http://herdeirodeaecio.blogspot.com.br/2008_06_01_archive.html 


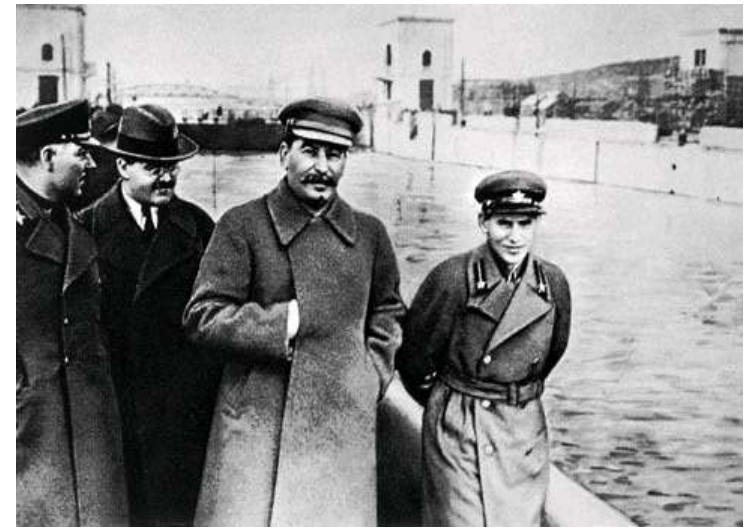

Imagem 03: Stalin com Nikolai Yezhov, comissário de transporte marítimo.

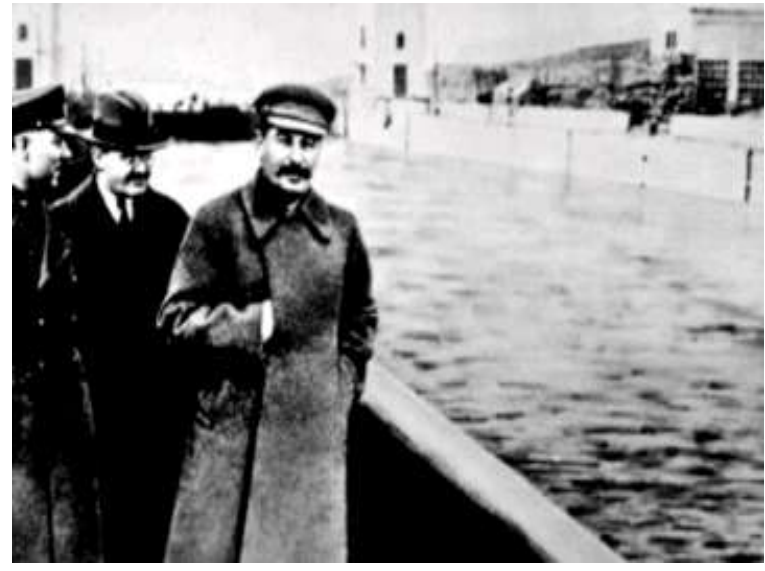

Imagem 04: Yezhov "sumiu"

A manipulação fotográfica faz recordar "1984" e suas constantes alterações nas fontes históricas. Interessei-me, sobretudo pela interpretação dos alunos sobre essas falsificações.

Para compreender as ideias dos alunos, há um campo na Educação Histórica conhecido como Cognição Histórica Situada, responsável por pesquisar a maneira que os sujeitos aprendem História. Conforme Schmidt $(2009$, p.38): 
(...)a cognição situada na História tem preocupação de investigar quais seriam os mecanismos de uma aprendizagem criativa e autônoma, que possam contribuir para que os alunos transformem informações em conhecimentos, apropriando-se das idéias históricas de forma mais complexa. O pressuposto é buscar a construção de uma literacia histórica, ou seja, da realização do processo de alfabetização histórica de cada um.

A ideia não é transformar os alunos em "mini-historiadores", mas contribuir para que eles desenvolvam o pensamento histórico, pois ainda para a autora:

(...)saber História não é a mesma coisa que pensar historicamente correto, pois o conhecimento histórico apreendido apenas como algo dado não desenvolve a capacidade de conferir significados à História e orientar aquele que aprende de acordo com a própria experiência histórica ( SCHMIDT, 2009, p.40).

Um ensino de história preocupado com o desenvolvimento da cognição histórica deve abranger muito mais que apenas fatos e datas: precisa incentivar a reflexão acerca dos eventos históricos, de modo que os alunos sejam capazes de interpretar e atribuir significados aos acontecimentos e, dessa forma, se situarem no mundo. Tal desenvolvimento, contudo, nunca é restrito apenas à sala de aula. Os alunos tem contato com a História de várias maneiras: através de jornais, filmes, livros, internet... Assim, para auxiliar o pensar histórico dos alunos, é fundamental compreender a visão deles sobre a História. Para que isso ocorra, a união do ensino com a pesquisa é vital:

(...)para que nos permita entender as idéias que estruturam as relações dos alunos com o passado e os tipos de passado que eles têm acesso. (...) Pesquisa e prática devem andar juntas com o desenvolvimento do currículo e com a contribuição dirigida por professores em estudos pilotos em pequena escala (LEE, 2006, p.147).

Assim, desenvolvi um "estudo piloto em pequena escala". Antes de investigar o olhar dos alunos sobre as manipulações fotográficas ocorridas no governo de Stálin, considerei importante fornecer informações de acontecimentos que ajudam a compreender melhor o momento que a União 
Soviética atravessava. Dessa forma eu, juntamente com meus colegas ${ }^{3}$ trabalhamos com os alunos a situação da Rússia no início do século $X X$, 0 Domingo Sangrento, o Encouraçado Potemkim e as duas revoluções de 1917. Discutimos o Manifesto Comunista, as ideias bolcheviques e mencheviques, o governo de Lênin e a disputa de sucessão entre Trotsky e Stálin.

A figura de Stálin permanece ainda hoje - mais de cinquenta anos após sua morte - enigmática. De acordo com Paulo Leminski: Dele [Stalin], só se pode falar em termos superlativos. Seus crimes são tão grandes quanto suas realizações. (LEMINSKI, 1986, p.89).

Stalin acabou com a NEP ${ }^{4}$ de Lênin e instaurou os planos quinquenais, com prioridade para a indústria de base e setores de infra-estrutura. Foi durante seu governo que a economia da União Soviética alavancou e passou a ser a segunda maior do mundo, competindo com os Estados Unidos após a Segunda Guerra Mundial. Nenhum outro país cresceu tanto no século XX. Contudo, foi também nesse período que milhões de pessoas foram presas, mandadas para campos de concentração ou assassinadas.

\begin{abstract}
Nessa época [anos 30 do século XX], Stálin começou a alimentar também uma aguda mania de perseguição, um medo crescente de ser traído, passando a viver com a idéia obsessiva de que não podia confiar em ninguém. Essa mania evoluiria para uma loucura paranóica que acabaria por leva-lo a querer destruir todos os que pudessem representar alguma ameaça para ele ou para o partido (HOOBLER, 1987, p.56).
\end{abstract}

Em uma época sem editores de imagem como o Photoshop, a equipe de Stálin conseguiu manipular fotografias fazendo desaparecer figuras antes importantes para a União Soviética. As fotografias eram recortadas e o corte dissimulado com um aerógrafo (espécie de pistola de ar comprimido que espalha a tinta uniformemente) e então a foto modificada era novamente fotografada e essa nova versão transformava-se na "original".

\footnotetext{
${ }^{3}$ Luciano von Frühauf e Maria Pessatti

4 NEP = Nova Política Econômica, colocada em prática em 1921, tinha como objetivo recuperar a economia. Permitia que pequenas empresas privadas pudessem existir.
} 
Assim, a equipe de Stalin "reescrevia o passado", tal como o protagonista de 1984, "apagando" pessoas que pudessem representar algum perigo ou abalar de alguma forma o seu governo.

Essa manipulação nas fotografias ou "lugares de memória" impôs uma memória, a memória oficial, "enquadrada", já que houve um "trabalho de enquadramento":

O trabalho de enquadramento da memória se alimenta do material fornecido pela história. Esse material pode sem dúvida ser interpretado e combinado a um sem-número de referências associadas; guiado pela preocupação não apenas de manter as fronteiras sociais, mas também de modificá-las, esse trabalho reinterpreta incessantemente 0 passado em função dos combates do presente e do futuro (POLLAK, 1989, p. 11).

Quais as conseqüências dessas alterações fotográficas? Será que é possível manipular os registros de tal modo que as pessoas com o tempo esqueçam de personagens importantes para a história do país? O que os alunos do segundo ano do ensino médio pensam a respeito?

Para tentar responder à última questão, foi entregue aos estudantes as duas fotografias que aparecem neste artigo e suas versões modificadas. Foi entregue, também, uma folha com alguns questionamentos para orientá-los no trabalho, que ocorreu em sala de aula depois de já terem sido discutidos os conteúdos referentes à Revolução Russa.

Além de investigar as ideias históricas dos alunos e as relações que eles fazem entre passado/presente, outro objetivo da atividade era fazer com que eles percebessem que as fontes históricas também podem ser manipuladas, e que as interpretações acerca do passado são construções baseadas nessas fontes. Como mostram Cainelli e Tuma (2009, p.212): Ensinar a criança a observar, analisar e identificar a História estudada como uma construção humana permite que ela entenda a provisoriedade do conhecimento histórico, identificando-o como produto da investigação histórica.

Nas respostas, os alunos demonstraram entendimento sobre essa questão quando perguntados se seria possível "apagar" alguém da história: 
Aluno A:

(...) da história também acho possível, considerando que se elimine "todos" a sua volta.

Aluno B:

Totalmente não. Sempre irá haver quem conte. $O$ que acontece é que o conhecimento da história de certas pessoas é crucial para o início das revoluções.

Aluno C:

(...) um governo nunca será capaz de fazer com que uma pessoa não tenha existido, pois a pessoa sempre deixa ou faz história, nem que seja curta.

A História, que é escrita de acordo com as fontes disponíveis em cada período e portanto pode deixar de contemplar certos personagens se não há referências a estes - ou se "todos a sua volta são eliminados", pode também servir de exemplo e guiar para as ações no futuro, como abordado pelo Aluno $B$, que também ressaltou a importância da memória para a história, pois a lembrança de um indivíduo, seu relato, contribuiria para que alguém não fosse "apagado" dela. Já o Aluno C demonstrou ter apreendido que a História é ação humana, construída por todos os sujeitos.

E quais pessoas eram "apagadas"? Qual o motivo dessas intervenções? Segundo os alunos:

Aluno D:

Acredito que o que levou Stálin a cometer essas atitudes foi o medo de perder o poder, o medo de que outros intelectuais, como Trotski, o derrubassem e assumissem o governo da URSS.

Aluno E:

Acho que era pelo medo dessas pessoas se oporem contra seu governo ou que pudessem revolucionar o momento.

Aluno $\mathrm{F}$ :

O governo se "livrava" das pessoas que eram contra ele, pelo fato de tentar garantir sua sobrevivência. Faz com que essas pessoas nunca tenham existido. Assim, talvez os pensamentos dessas pessoas não serão passados à frente.

Aluno G:

As piores coisas acontecem com as melhores intenções. 
Em grande parte dos textos, o "medo de perder o poder" aparece como uma das causas para Stálin e sua equipe terem feito o que fizeram. De fato, nas biografias e depoimentos sobre o líder da URSS, é comum encontrarmos tal referência:

Stálin era incapaz de ver o mundo senão pelo prisma de seus próprios medos e ambições. Era difícil, para qualquer estrangeiro que se aproximasse dele, descobrir com quem estava tratando. Às vezes, Stálin falava como se estivesse considerando apenas os interesses do movimento proletário; outras vezes, apenas os seus próprios interesses (KENNAN, apud HOOBLER, 1987, p.61).

Mas será que Stálin conseguiu mesmo fazer desaparecer figuras antes importantes dentro do partido? É possível eliminar todos os traços de existência de uma pessoa? O que os alunos pensam sobre isso? Para eles:

\begin{abstract}
Aluno $\mathrm{H}$ :
O governo não é capaz disso pois a pessoa sempre vai estar na memória de alguém, mas chega bem perto de fazer a pessoa nunca ter existido, consegue induzir, obrigar as pessoas a não falaram mais da outra pessoa esquecida.
\end{abstract}

Aluno I:

Dependendo do que a pessoa proporcionou ao país de positivo pode ser lembrado para sempre pelo povo (...)

Aluno J:

Não é possível fazer com que uma pessoa nunca tenha existido porque pode apagar ela de todos os registros, mas ela sempre estará na memória das pessoas que a conheciam.

Aluno L:

Não acredito que "apagar" pessoas seja possível pois estas sempre ficarão na memória e amigos e familiares lutarão ao máximo por suas dignidades.

Nas respostas, é possível perceber a relação entre memória e história. Segundo a interpretação dos alunos, embora Stálin tenha conseguido apagar alguns personagens da história oficial (mesmo que apenas temporariamente), eles continuaram "vivos" no que Pollak chama de memórias "subterrâneas": 
Essas memórias subterrâneas que prosseguem seu trabalho de subversão no silêncio e de maneira quase imperceptível afloram em momentos de crise em sobressaltos bruscos e exarcebados. A memória entra em disputa. Os objetos de pesquisa são escolhidos de preferência onde existe conflito e competição entre memórias concorrentes (POLLAK, 1989, p.4).

Essa disputa entre a História oficial, alimentada por uma memória também oficial, e memórias subterrâneas torna-se evidente quando vemos as fotografias modificadas durante o stalinismo. Enquanto a memória coletiva nacional buscou apagar certos personagens, eles permaneceram na lembrança de seus conhecidos, como os alunos escreveram.

Muitas das modificações ganharam visibilidade após o lançamento do livro The Comissar Vanishes, em 1997. O autor David King passou trinta anos coletando material onde era possível identificar a foto original da cópia:

Cada foto adulterada esconde uma tragédia pessoal em que se conhece a vítima e seu destino. King narra casos de viúvas que, com medo da polícia, rasgaram as fotos do marido executado por ordem de Stalin, de filhos que jamais mencionaram o nome do próprio pai (KLINTOWITZ, 1997, p.64).

A memória coletiva forjada pela equipe de Stálin é um claro exemplo do que Pollak chamou de "o caráter destruidor, uniformizador e opressor da memória coletiva". Houve um grande esforço para construir uma memória, contudo, os crimes cometidos por ordem de Stálin começaram a ser denunciados logo após sua morte, no XX Congresso do Partido Comunista da União Soviética (1956), e houve uma reviravolta na percepção da história e as memórias, antes subterrâneas, começaram a ganhar visibilidade.

A União Soviética começou o processo de desestalinização e documentos vieram à tona, revelando os crimes cometidos durante o governo de Stálin e as falsificações historiográficas. 
Hoje, temos acesso tanto aos originais quanto às cópias e sabemos qual é qual. A ideia de "apagar" alguém parece atemorizante, contudo, será que algo assim não tem como se tornar realidade novamente?

O espaço da sala de aula deve servir para questionamentos acerca do passado, presente e futuro. É o local para debate e ao professor, cabe não somente ensinar história, mas também fazer os alunos refletirem historicamente, conforme nos diz Ivo Matozzi (1999, p.37):

El enseñante de historia tiene una doble obligación: primero, hacer que los alumnos aprendan un sistema de conocimientos, y segundo, que desarrollen un conjunto de estructuras mentales y de habilidades operativas recurrentes en el conocimiento historiográfico. El objetivo de las dos tareas consiste en crear las condiciones para que los alumnos puedan estabelecer y perfeccionar la forma de pensamiento que les permita comprender la realidad y las experiências en términos históricos ${ }^{5}$.

Compreender a realidade e as experiências em termos históricos permite que os alunos sejam capazes de examinar o presente, fazendo relações com o passado.

Quando questionados se seria possível fazer hoje algo parecido com o que o governo de Stálin fez, os alunos argumentaram que:

Aluno M:

Acho que até hoje é possível, talvez até mais fácil que antigamente, mas o risco da pessoa escapar acho que é maior.

Aluno N:

Ao meu ver sim, é possível apagar uma pessoa, já que dizem que quem não tem certidão de nascimento é como se não existisse. Então se você já tem uma vida constituída e "alguém" apagar os seus registros gerais (RG) você passa a não existir, mesmo estando vivo.

5 O professor de História tem uma obrigação dupla: primeiro, fazer com que os alunos aprendam conhecimentos, e segundo, que desenvolvam um conjunto de estruturas mentais e de habilidades operacionais recorrentes no conhecimento historiográfico. 0 objetivo consiste em criar as condições para que os alunos possam estabelecer e aperfeiçoar uma forma de pensamento que lhes permita compreender a realidade e as experiências em termos históricos [tradução nossa]. 
Aluno C:

Atualmente, isso é mais complicado ainda, pois estamos em um mundo globalizado. Ao nascer uma criança, uma pessoa do outro lado do mundo pode saber em questão de segundos, e isso se propaga loucamente, até ser impossível de evitar.

Aluno O:

Hoje apagar da história é praticamente impossível, pois o conhecimento e a informação tem uma divulgação e um acesso muito amplo.

Aluno P:

Atualmente as pessoas possuem muitos dados, as redes sociais estão maiores, está mais difícil de controlar o que acontece, etc.

Para a maior parte dos alunos, seria mais difícil "apagar" alguém atualmente. Na resposta do Aluno $\mathrm{P}$ é possível perceber vestígios do discurso vigente de uma sociedade altamente burocrática, como a nossa.

Nota-se também nas respostas acima a análise sobre o tempo presente, globalizado. O processo de integração dos mercados também facilita a troca de informações e a internet contribuiu muito para a circulação dos acontecimentos, como citado pelo Aluno C.

Outro fenômeno contemporâneo e lembrado pelos alunos é a importância das redes sociais (também chamadas de redes de relacionamentos) como um suporte de memória. Criadas nesta década, as redes sociais difundiram-se e hoje somam milhões de usuários em seus mais variados tipos. Só o Facebook possui mais de 500.000 .000 de internautas cadastrados, o que equivale a mais de $8 \%$ da população mundial.

Em um questionário investigativo realizado com os alunos no período em que observamos as aulas, a maioria deles declarou participar dessas redes. Eles assumiram, também, passar longas horas navegando na internet, que como lembrou o Aluno $P$, é um espaço mais difícil de ser controlado. 


\title{
Considerações Finais
}

\begin{abstract}
Se o Partido tem o poder de agarrar o passado e dizer que este ou aquele acontecimento nunca se verificou - não é mais aterrorizante do que a simples tortura e a morte? O Partido dizia que a Oceania jamais fora aliada da Eurásia. Ele, Winston Smith, sabia que a Oceania fora aliada da Eurásia não havia senão quatro anos. Onde, porém, existia esse conhecimento? Apenas em sua consciência, o que em todo caso devia ser logo aniquilado. E se todos os outros aceitassem a mentira imposta pelo Partido - se todos os anais dissessem a mesma coisa -, então a mentira se transformava em história, em verdade (ORWELL, 2005, p. 36).
\end{abstract}

Stálin, líder da União das Repúblicas Socialistas Soviéticas por quase trinta anos, tem algumas vezes a alcunha "Grande Irmão" associada ao seu nome, em uma referência ao livro escrito por George Orwell.

Como dito no início, 1984 é um relato fictício. Orwell, contudo, inspirou-se em modelos totalitários para escrevê-lo. O livro serve como alerta do que poderia acontecer em um mundo totalmente controlado pelo governo em que até os pensamentos são fiscalizados.

A História, de certa forma, também tem o papel de nos alertar. Estudar e refletir com os alunos sobre acontecimentos passados pode ser uma forma de evitar que eles venham a se repetir futuramente.

Cada vez mais o ensino de história deixa de ser um apanhado de fatos e volta-se à reflexão e ao aprimoramento da consciência histórica dos alunos. Para tanto, é necessário descobrir como os sujeitos pensam e aprendem história, já que este processo está longe de se restringir apenas à sala de aula. A junção de ensino e pesquisa é essencial para isso.

Ao realizar meu estágio no Colégio de Aplicação, percebi como é importante desenvolver atividades investigativas com os estudantes, tanto para fazê-los examinar mais atentamente determinados temas, como para entender as ideias deles e poder trabalhá-las melhor em sala de aula. Analisando as fotografias modificadas durante o stalinismo, os alunos puderam refletir também sobre os motivos de tais alterações e fizeram relação com o conteúdo apreendido e o presente. A atividade revelou a profundidade da compreensão de alguns alunos e a capacidade de analisar a realidade de maneira crítica. Eles também puderam perceber que os 
eventos em história sempre se relacionam, e não são fragmentados como por vezes as aulas ou o livro didático possam fazer parecer.

Foi possível, ainda, trabalhar com a relação entre memória e história. A história enquanto construção humana, feita por todos, mas também dependente das fontes do período, por vezes manipuladas de acordo com interesses políticos, e a memória enquanto resistência, que tenta sobreviver nas condições mais difíceis. Para os alunos, contudo, por mais que os registros sejam modificados e pessoas sejam apagadas, elas permanecerão na memória de seus conhecidos e não serão esquecidas, mesmo que a história oficial tente provar o contrário.

\section{Referências}

CAINELLI, M.; TUMA, M. História e Memória na construção do pensamento histórico: uma investigação em Educação Histórica. Revista HISTEDBR online, Campinas, n. 34. Disponível em: < http://www.histedbr.fae.unicamp.br/revista/edicoes/34/ >. Acesso em: 07 set. 2011.

ORWELL, G. 1984. São Paulo: Companhia Editora Nacional, 2005.

HOOBLER, D.; HOOBLER T. Stálin. São Paulo: Nova cultural, 1987.

KLINTOWITZ, J. O pai da mentira. Veja, São Paulo, n. 1522, p.62-65, 19 nov. 1997. Disponível em: <http://veja.abril.com.br/191197/p_062.html>. Acesso em: 01 nov. 2010.

LEE, Peter. Em direção a um conceito de literacia histórica. Educar, Curitiba, Especial, 2006.

LEMINSKI, P. Trotski: a paixão segundo a revolução. São Paulo: Brasiliense, 1986.

MATTOZZI, Ivo. La transposicion del texto historiográfico: un problema crucial de la didáctica de la História. Teoria y Didáctica de las Ciências Sociales. Barcelona: n.4, 1999

NORA, P. Entre memória e História: a problemática dos lugares. Projeto História, São Paulo, n.10, dez. 1993

POLLAK, M. Memória, Esquecimento, Silêncio. Estudos Históricos, Rio de Janeiro, v. 2, n. 3, 1989. 
SCHMIDT, M. A. Cognição Histórica situada: que aprendizagem histórica é esta?. In SCHMIDT, M. A.; BARCA, I. (Org.). Aprender História:

perspectivas da educação histórica. Ijuí: Editora UNIJUI, 2009. 